\title{
KINERJA YANG DIPENGARUHI LINGKUNGAN KERJA, MOTIVASI DAN KOMPENSASI PADA KARYAWAN PERUSAHAAN MANUFAKTUR
}

\author{
Ronny Hardiansyah Wicaksana \\ Marjam Desma Rahadhini \\ Alwi Suddin \\ ronnywicaksana@yahoo.com \\ m_rahadhini@yahoo.com \\ alwisuddin11@gmail.com
}

Fakultas Ekonomi Universitas Slamet Riyadi, Surakarta, Indonesia

\section{Info Artikel}

Sejarah Artikel:

Diterima

Disetujui

Dipublikasikan

Keywords:

work

environment;

motivation;

compensation;

employee

performance

\begin{abstract}
Abstrak
$\overline{\text { Keberhasilan sebuah perusahaan sangat erat berkaitan dengan }}$ kinerja dari karyawan yang ada dalam perusahaan. Karyawan mengemban tugas dan fungsi dalam perusahaan. Meningkatnya kinerja perusahaan merupakan indikator dari keberhasilan suatu perusahaan. Tujuan penelitian ini untuk menganalisis: 1) pengaruh lingkungan kerja terhadap kinerja karyawan, 2) pengaruh motivasi terhadap kinerja karyawan, 3) pengaruh kompensasi terhadap kinerja karyawan, dan 4) variabel yang dominan pengaruhnya terhadap kinerja karyawan. Jenis penelitian ini adalah survei pada karyawan CV Panca Putra di Karanganyar. Jenis data menggunakan data kualitatif dan data kuantitatif. Sumber data menggunakan sumber data primer dan data sekunder. Populasi target adalah karyawan bagian produksi sebanyak 534 karyawan. Sampel ditentukan 80 karyawan dengan proportional cluster random sampling. Pengumpulan data menggunakan kuesioner. Analisis data menggunakan uji regresi linear berganda. Hasil penelitian menunjukkan bahwa lingkungan kerja, motivasi dan kompensasi berpengaruh terhadap kinerja karyawan. Kompensasi merupakan variabel yang dominan pengaruhnya terhadap kinerja karyawan, karena nilai koefisien regresinya 0,473; lebih besar daripada lingkungan kerja (0,261), dan motivasi $(0,393)$
\end{abstract}




\begin{abstract}
The success of a company is closely related to the performance of existing employees within the company. Employees carry out the task and functions within the company. Increased corporate performance is an indicator of the success of a company. The purpose of this study is to analyze: 1) the influence of work environment on employee performance, 2) the influence of motivation on employee performance, 3) the effect of compensation on employee performance, and 4) the dominant variable influence on employee performance. This type of research is a survey on employees of $C V$ Panca Putra in Karanganyar. Types of data use qualitative and quantitative data. Data sources use primary and secondary data sources. Target population is employees of production as much as 534 employees. The sample was determined by 80 employees with proportional cluster random sampling. Data collection using questionnaires. Data analysis using multiple linear regression test. The results showed that the work environment, motivation and compensation effect on employee performance. Compensation is a dominant variable affecting employee performance, because the value of regression coefficient 0.473 ; greater than the working environment (0.261), and motivation (0.393)
\end{abstract}

\title{
PENDAHULUAN
}

Manajemen sumber daya manusia berfungsi untuk mengelola unsur manusia, sehingga sumber daya manusia akan menjadi penentu dari keberhasilan perusahaan, karena pada dasarnya manusia merupakan penggerak dan penentu tercapainya tujuan organisasi perusahaan. Keberhasilan dalam sebuah perusahaan sangat erat hubungannya dengan kinerja dari karyawan yang ada, karena karyawan mengemban fungsi serta kewajiban dalam perusahaan. Semakin baik kinerja dari karyawan, maka akan berdampak positif terhadap meningkatnya kinerja karyawan. Meningkatnya kinerja perusahaan merupakan indikator dari keberhasilan suatu perusahaan. Kinerja adalah tentang apa yang dikerjakan karyawan dan bagaimana cara mengerjakannya. "Kinerja 
merupakan hasil pekerjaan yang mempunyai hubungan kuat dengan tujuan strategis organisasi, kepuasan konsumen dan memberikan kontribusi ekonomi” (Wibowo, 2007). Faktor yang dapat meningkatkan kinerja karyawan antara lain lingkungan kerja, motivasi dan kompensasi.

Lingkungan kerja sangat penting untuk diperhatikan manajemen. Keberhasilan peningkatan kinerja menuntut organisasi mengetahui sasaran kinerja. Sasaran kinerja yang timbul dari dalam diri karyawan akan membentuk kekuatan diri dan apabila lingkungan kerja mendukung maka pencapaian kinerja akan lebih mudah. Lingkungan kerja yang baik menjadikan semangat kerja karyawan meningkat sehingga kinerja juga meningkat, sebaliknya lingkungan kerja yang tidak memadai dapat menurunkan kinerja karyawan (Moekijat, 2007; Mangkunegara, 2012; Murdiyanto, 2012).

Motivasi kerja sebagai sesuatu yang menimbulkan dorongan atau semangat kerja (Martoyo, 2007). Dorongan merupakan gerak jiwa dan jasmani untuk berbuat, sehingga motif tersebut merupakan suatu kekuatan yang menggerakkan manusia untuk bertingkah laku dan mempunyai tujuan tertentu. Motivasi sebagai dorongan yang bersifat internal maupun eksternal dalam melakukan tindakan tertentu.

Kompensasi merupakan pendapatan yang diterima karyawan sebagai imbalan atas jasa yang diberikan kepada perusahaan, kompensasi dapat berupa uang atau barang. Kebijakan pemberian kompensasi dimaksudkan untuk meningkatkan motivasi dalam meningkatkan kinerja karyawan. "Karyawan yang diliputi oleh rasa tidak puas atas kompensasi yang diterimanya, maka berdampak negatif bagi perusahaan dan apabila kompensasi tidak dapat terselesaikan maka dapat menurunkan kinerja" (Siagian, 2007).

\section{METODE}

Penelitian ini adalah penelitian survai pada karyawan bagian produksi CV Panca Putra di Karanganyar. Alasan pemilihan obyek adalah persaingan antar perusahaan manufaktur membutuhkan kinerja karyawan yang maksimal, sehingga manajemen perusahaan perlu meningkatkan kinerja karyawan melalui lingkungan kerja, motivasi dan kompensasi yang diberikan kepada karyawan. Jenis data yang digunakan adalah data kualitatif dan kuantitatif. Sumber data penelitian adalah data primer dan sekunder. Populasi penelitian adalah karyawan bagian produksi CV Panca Putra di Karanganyar sebanyak 534 karyawan, sebagai berikut: 
Tabel 1.

Jumlah Karyawan CV Panca Putra Karanganyar

\begin{tabular}{|c|c|c|}
\hline No & Posisi & $\Sigma$ Karyawan \\
\hline 1 & Staf Produksi & 63 \\
\hline 2 & Washing & 96 \\
\hline 3 & Pelet & 103 \\
\hline 4 & Mixshing & 96 \\
\hline 5 & HD Roll & 89 \\
\hline 6 & Finishing & 87 \\
\hline
\end{tabular}

Sumber: CV Panca Putra Karanganyar, 2017

Teknik pengambilan sampel menggunakan metode proportional cluster random sampling, sampel ditentukan sebanyak 15\% dari 534 karyawan, sehingga diperoleh 80 karyawan pada masing-masing posisi, dengan proporsi sampel sebagai berikut:

Tabel 2.

Proporsi Pengambilan Sampel

\begin{tabular}{clccc}
\hline No & \multicolumn{1}{c}{ Posisi } & $\boldsymbol{\Sigma}$ Karyawan & Sampling & Jumlah sampel \\
\hline 1 & Staf Produksi & 63 & $15 \%$ x 63 & 9 \\
2 & Washing & 96 & $15 \%$ x 96 & 14 \\
3 & Pelet & 103 & $15 \%$ x 103 & 15 \\
4 & Mixshing & 96 & $15 \%$ x 96 & 14 \\
5 & HD Roll & 89 & $15 \%$ x 89 & 13 \\
6 & Finishing & 87 & $15 \%$ x 87 & 13 \\
\hline \multicolumn{2}{c}{ Jumlah } & 534 & & 80 \\
\hline
\end{tabular}

Sumber: Data primer diolah, 2017

Adapun definisi operasional variabel yang digunakan:

1. Lingkungan Kerja

Lingkungan kerja adalah adalah segala sesuatu yang ada di sekitar karyawan yang mempengaruhi tugas-tugas yang dibebankan pada karyawan. Indikator lingkungan kerja meliputi lingkungan kerja fisik dan lingkungan kerja non fisik, yaitu: penerangan kerja, temperature/suhu udara, kebersihan lingkungan, ruang gerak karyawan, pewarnaan, kebisingan, keamanan kerja, hubungan dengan sesama rekan kerja, hubungan kerja dengan atasan.

2. Motivasi Kerja 
Motivasi kerja adalah faktor-faktor yang berasal dari dalam diri karyawan maupun dari luar yang menggerakkan dan mengarahkan perilakunya untuk bekerja dengan lebih baik guna mencapai tujuan yang telah ditetapkan. Indikator motivasi kerja adalah: motif bekerja, penghargaan, tantangan, tanggung jawab, keterlibatan, pengembangan dan kesempatan.

3. Kompensasi

Kompensasi adalah pemberian perusahaan atas hasil kerja yang telah dilakukan karyawan, kesejahteraan yang diberikan berupa materi ataupun non materi. Indikator kompensasi adalah kompensasi insentif, kompensasi tunjangan dan jasa, kompensasi pelengkap dan kompensasi keamanan dan kesehatan.

4. Kinerja Karyawan

Kinerja adalah tingkat keberhasilan karyawan dalam melaksanakan tugas dan tanggung jawabnya secara individu maupun kelompok. Indikator kinerja terdiri dari kualitas kerja, kuantitas kerja, tanggung jawab, inisiatif, kerja sama dan ketaatan.

Pengumpulan data menggunakan kuesioner, dengan skala likert skor 1-5 (sangat tidak setuju sampai dengan sangat setuju). Uji instrumen penelitian dengan uji validitas (product moment pearson correlation) dan uji reliabilitas (cronbach alpha). Uji asumsi klasik yang digunakan uji multikolinearitas, uji autokorelasi, uji heteroskedastisitas, dan uji normalitas. Sedangkan pengujian hipotesis menggunakan analisis regresi linear berganda. Analisis ini digunakan untuk menganalisis pengaruh dari variabel bebas (lingkungan kerja, motivasi kerja dan kompensasi) terhadap variabel terikat (kinerja karyawan), dengan rumus:

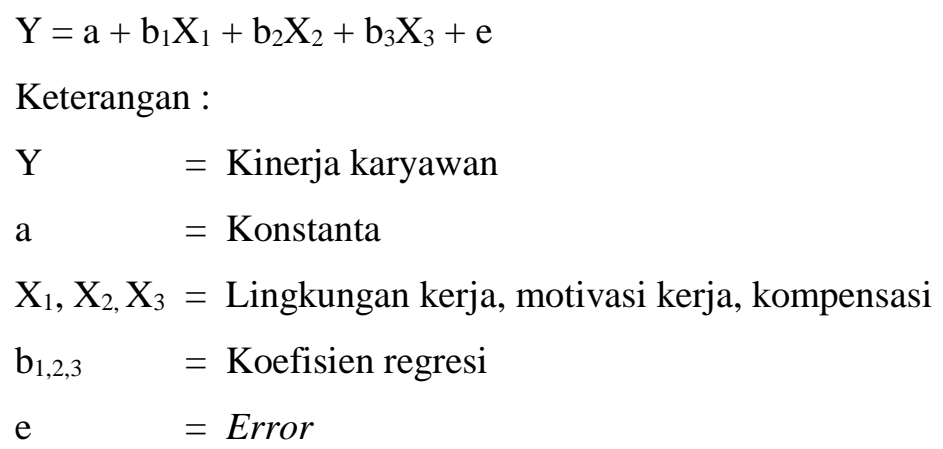

\section{HASIL DAN PEMBAHASAN}


Tabel 3.

Responden Berdasarkan Jenis Kelamin, Usia, Pendidikan, dan Masa Kerja

\begin{tabular}{|c|c|c|}
\hline Jenis Kelamin & Frekuensi (orang) & Persentase (\%) \\
\hline Pria & 58 & 72,5 \\
\hline Wanita & 22 & 27,5 \\
\hline Total & 80 & 100 \\
\hline \multicolumn{3}{|l|}{ Usia } \\
\hline$<30$ tahun & 24 & 30,0 \\
\hline $31-40$ tahun & 26 & 32,5 \\
\hline$>40$ tahun & 30 & 37,5 \\
\hline Total & 80 & 100 \\
\hline \multicolumn{3}{|l|}{ Pendidikan } \\
\hline SD & 0 & 0,0 \\
\hline SMP & 0 & 0,0 \\
\hline SMA & 62 & 77,5 \\
\hline PT & 18 & 22,5 \\
\hline Total & 80 & 100 \\
\hline \multicolumn{3}{|l|}{ Masa Kerja } \\
\hline$<10$ tahun & 12 & 15,0 \\
\hline $10-20$ tahun & 49 & 61,3 \\
\hline$>20$ tahun & 19 & 23,7 \\
\hline Total & 80 & 100 \\
\hline
\end{tabular}

Sumber : Data primer yang diolah, 2017

Pengujian validitas dengan menggunakan product moment pearson correlation adalah valid, karena besarnya $p$ value $<0,05$ sehingga instrumen penelitian layak digunakan. Sedangkan pengujian reliabilitas mengenai variabel lingkungan kerja 0,858 ; motivasi 0,898 ; kompensasi 0,888 ; kinerja karyawan 0,897 menunjukkan reliabel karena nilai cronbach's alpha $>0,60$.

Pengujian asumsi klasik (uji multikolinearitas, uji autokorelasi, uji heteroskedastisitas, dan uji normalitas) semua telah lolos uji, sehingga pengujian hipotesis dapat dilakukan.

Tabel 4. 
Hasil Uji Regresi Linear Berganda

Coefficients $^{\mathrm{a}}$

\begin{tabular}{|ll|r|r|r|r|r|}
\hline \multirow{2}{*}{ Model } & \multicolumn{2}{|c|}{$\begin{array}{c}\text { Unstandardized } \\
\text { Coefficients }\end{array}$} & \multicolumn{2}{c|}{$\begin{array}{c}\text { Standardized } \\
\text { Coefficients }\end{array}$} & & \\
\cline { 2 - 5 } & \multicolumn{1}{|c|}{$\mathrm{B}$} & Std. Error & \multicolumn{1}{c|}{ Beta } & \multicolumn{1}{c|}{$\mathrm{t}$} & \multicolumn{1}{c|}{ Sig. } \\
\hline 1 & (Constant) & -4.154 & 3.509 & & -1.184 & .240 \\
& Lingkungan Kerja & .261 & .065 & .252 & 4.006 & .000 \\
& Motivasi & .393 & .065 & .402 & 6.079 & .000 \\
& Kompensasi & .473 & .062 & .524 & 7.630 & .000 \\
\hline
\end{tabular}

a. Dependent Variable: Kinerja

Sumber: Data primer diolah, 2017

Hasil analisis regresi linear berganda diperoleh persamaan regresi:

$$
Y=-4,154+0,261 X_{1}+0,393 X_{2}+0,473 X_{3} .
$$

Hasil persamaan regresi dan interpretasi dari analisis regresi berganda adalah: Nilai konstanta (a) bertanda negatif, yaitu -4,154 artinya apabila lingkungan kerja, motivasi dan kompensasi sama dengan nol (0) maka kinerja karyawan mengalami penurunan; Nilai koefisien regresi variabel lingkungan kerja $\left(\mathrm{X}_{1}\right)$ yaitu sebesar 0,261 artinya lingkungan kerja berpengaruh positif terhadap kinerja karyawan;Nilai koefisien regresi variabel motivasi $\left(\mathrm{X}_{2}\right)$ yaitu sebesar 0,393 artinya motivasi berpengaruh positif terhadap kinerja karyawan; Nilai koefisien regresi variabel kompensasi $\left(\mathrm{X}_{3}\right)$ yaitu sebesar 0,473 artinya kompensasi berpengaruh positif terhadap kinerja karyawan.

Hasil penelitian menunjukkan nilai koefisien regresi lingkungan kerja $(0,261)$, motivasi (0,393) dan kompensasi (0,473); karena 0,473>0,261 dan 0,393 maka kompensasi merupakan variabel yang dominan pengaruhnya terhadap kinerja karyawan.

Tabel 5.

Hasil Uji t 
Coefficients $^{\mathrm{a}}$

\begin{tabular}{|ll|r|r|r|r|r|}
\hline \multirow{2}{*}{ Model } & \multicolumn{2}{|c|}{$\begin{array}{c}\text { Unstandardized } \\
\text { Coefficients }\end{array}$} & \multicolumn{2}{c|}{$\begin{array}{c}\text { Standardized } \\
\text { Coefficients }\end{array}$} & & \\
\cline { 3 - 5 } & \multicolumn{1}{|c|}{$\mathrm{B}$} & \multicolumn{1}{c|}{ Std. Error } & \multicolumn{1}{c|}{ Beta } & \multicolumn{1}{c|}{$\mathrm{t}$} & \multicolumn{1}{c|}{ Sig. } \\
\hline 1 & (Constant) & -4.154 & 3.509 & & -1.184 & .240 \\
& Lingkungan Kerja & .261 & .065 & .252 & 4.006 & .000 \\
& Motivasi & .393 & .065 & .402 & 6.079 & .000 \\
& Kompensasi & .473 & .062 & .524 & 7.630 & .000 \\
\hline
\end{tabular}

a. Dependent Variable: Kinerja

Sumber: Data primer diolah, 2017

Hasil perhitungan uji t variabel lingkungan kerja diperoleh nilai t sebesar 4,006 dengan $p$ value $0,000<0,05$ maka Ho ditolak, artinya lingkungan kerja berpengaruh signifikan terhadap kinerja karyawan. Hasil perhitungan uji $\mathrm{t}$ variabel motivasi diperoleh nilai t sebesar 6,079 dengan $p$ value 0,000 $<0,05$ maka Ho ditolak, artinya motivasi berpengaruh signifikan terhadap kinerja karyawan.Hasil perhitungan uji $\mathrm{t}$ variabel kompensasi diperoleh nilai t sebesar 7,630 dengan $p$ value $0,000<0,05$ maka Ho ditolak, artinya kompensasi berpengaruh signifikan terhadap kinerja karyawan.

Tabel 6.

Hasil Uji F

ANOVA ${ }^{\mathrm{b}}$

\begin{tabular}{|c|c|c|c|c|c|c|}
\hline Model & & $\begin{array}{c}\text { Sum of } \\
\text { Squares }\end{array}$ & df & Mean Square & $\mathrm{F}$ & Sig. \\
\hline \multirow[t]{3}{*}{1} & Regression & 1458.148 & 3 & 486.049 & 69.849 & $.000^{\mathrm{a}}$ \\
\hline & Residual & 528.852 & 76 & 6.959 & & \\
\hline & Total & 1987.000 & 79 & & & \\
\hline
\end{tabular}

a. Predictors: (Constant), Kompensasi, Lingkungan Kerja, Motivasi

b. Dependent Variable: Kinerja

Sumber: Data primer diolah, 2017

Hasil uji $\mathrm{F}$ diperoleh $p$ value $0,000<0,05$, maka Ho ditolak, sehingga model regresi tepat (fit) dalam memprediksi pengaruh lingkungan kerja, motivasi dan kompensasi terhadap kinerja karyawan.

Tabel 7. 
Hasil Uji Koefisien Determinasi

Model Summary

\begin{tabular}{|l|r|r|r|r|}
\hline Model & $\mathrm{R}$ & R Square & $\begin{array}{c}\text { Adjusted } \\
\text { R Square }\end{array}$ & $\begin{array}{r}\text { Std. Error of } \\
\text { the Estimate }\end{array}$ \\
\hline 1 & $.857^{\mathrm{a}}$ & .734 & .723 & 2.63791 \\
\hline
\end{tabular}

a. Predictors : (Constant), Kompensasi, Lingkungan Kerja, Motivasi

Sumber: Data primer diolah, 2017

Hasil uji koefisien determinasi diperoleh nilai adjusted $R$ square 0,723 hal ini berarti bahwa pengaruh yang diberikan oleh variabel lingkungan kerja, motivasi dan kompensasi terhadap kinerja karyawan sebesar 72,3\%; sedangkan sebesar 27,7\% dipengaruhi oleh variabel lain.

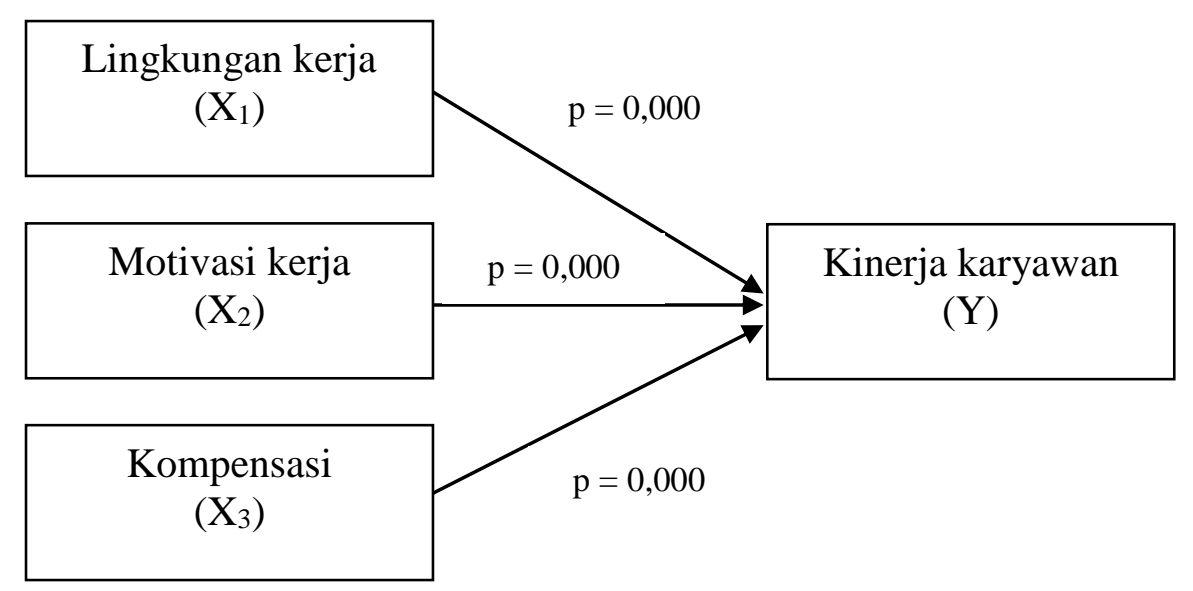

Sumber: Data yang diolah (2017)

Gambar 1. Hasil Uji Regresi Linier Berganda

Hasil penelitian menunjukkan bahwa lingkungan kerja berpengaruh terhadap kinerja karyawan. sehingga $\mathrm{H}_{1}$ yang menyatakan bahwa lingkungan kerja berpengaruh signifikan terhadap kinerja karyawan, terbukti. Hasil penelitian ini mendukung penelitian Murdiyanto (2012) menunjukkan bahwa lingkungan kerja berpengaruh signifikan terhadap kinerja karyawan. Hal ini berarti CV Panca Putera perlu meningkatkan lingkungan kerja perusahaan melalui meningkatkan komunikasi antara karyawan dengan pimpinan dengan program-program seperti outbound 
ataupun rekreasi bersama antar karyawan kantor sehingga dapat lebih mempererat hubungan antar karyawan dan juga hubungan karyawan dengan pimpinan.

Hasil penelitian menunjukkan bahwa motivasi berpengaruh terhadap kinerja karyawan. sehingga $\mathrm{H}_{2}$ yang menyatakan bahwa motivasi berpengaruh signifikan terhadap kinerja karyawan, terbukti. Hasil penelitian ini mendukung penelitian Setyani (2014), Wijaya dan Andreani (2014) serta Nurcahyani dan Adnyani (2016) bahwa motivasi berpengaruh signifikan terhadap kinerja karyawan. Hal ini berati CV Panca Putera perlu meningkatkan motivasi kerja karyawan melalui pemberian insentif bagi karyawan yang berprestasi, memberikan promosi jabatan bagi karyawan yang dianggap layak dan mampu mengemban tugas baru sesuai dengan kemampuan dan keahliannya.

Hasil penelitian menunjukkan bahwa kompensasi berpengaruh terhadap kinerja karyawan. sehingga $\mathrm{H}_{3}$ yang menyatakan bahwa kompensasi berpengaruh signifikan terhadap kinerja karyawan, terbukti. Hasil ini juga mendukung penelitian Wijaya dan Andreani (2015), Nurcahyani dan Adnyani (2016) yang menunjukkan bahwa kompensasi berpengaruh signifikan terhadap kinerja karyawan. Hal ini berarti CV Panca Putera dalam upaya meningkatkan kinerja karyawan melalui kompensasi dapat dilakukan dengan meningkatkan gaji secara berkala ataupun memberikan bonus-bonus di tengah semester atau di akhir tahun supaya karyawan dapat lebih tenang dalam bekerja.

\section{PENUTUP}

Sumber daya manusia akan menjadi penentu dari keberhasilan perusahaan. Keberhasilan sebuah perusahaan sangat erat kaitannya dengan kinerja karyawan yang ada. Semakin baik kinerja dari karyawan maka akan berdampak positif terhadap peningkatan kinerja karyawan. Faktor yang dapat meningkatkan kinerja karyawan antara lain lingkungan kerja, motivasi dan kompensasi. Lingkungan kerja sangat penting untuk diperhatikan manajemen. Demikian juga motivasi sebagai dorongan yang merupakan suatu kekuatan yang menggerakkan manusia untuk bertingkah laku dan mempunyai tujuan tertentu. Sedangkan kompensasi merupakan pendapatan yang diterima karyawan sebagai imbalan atas jasa yang diberikan kepada perusahaan. Kebijakan kompensasi dilakukan untuk meningkatkan motivasi dalam meningkatkan kinerja karyawan. Saran yang dapat diberikan pada CV Panca Putera, hendaknya 
perusahaan memberikan fasilitas untuk outbound ataupun rekreasi bagi karyawan untuk lebih mempererat komunikasi antar karyawan maupun antara karyawan dengan pimpinan. Motivasi juga dapat dilakukan dengan memberikan insentif ataupun promosi jabatan bagi karyawan yang berprestasi, dan memberikan penghargaan pada karyawan yang berjasa pada perusahaan. Sedangkan kompensasi dapat diberikan dengan lebih meningkatkan pemberian gaji secara berkala serta memberikan bonus di akhir tahun untuk meningkatkan kenyamanan karyawan dalam bekerja.

\section{DAFTAR PUSTAKA}

Arikunto, Suharsimi. (2010). Prosedur Penelitian Suatu Pendekatan Praktek. Rineka Cipta. Jakarta.

Dharma, Agus. (2010). Manajemen Supervisi: Petunjuk Praktis Bagi Para Supervisor. Raja Grafindo Persada. Jakarta.

Ghozali, Imam. (2011). Aplikasi Analisis Multivariate dengan Program SPSS. Badan Penerbit Universitas Diponegoro. Semarang.

Gomes, Faustino Cardoso. (2008). Manajemen Sumberdaya Manusia, BPFE, Yogyakarta.

Handoko, T. Hani. (2009). Manajemen Personalia dan Sumber Daya Manusia. BPFE. Yogyakarta.

Mangkunegara, Anwar Prabu. (2012). Manajemen Sumber Daya Manusia. Remaja Rosdakarya. Bandung.

Mardiana. (2015). Manajemen Produksi. Badan Penerbit IPWI. Jakarta.

Martoyo, Susilo. (2007). Manajemen Sumber Daya Manusia, BPFE. Yogyakarta.

Moekijat. (2007). Manajemen Sumberdaya Manusia (Manajemen Kepegawaian). Mandar Maju. Bandung.

Munandar, Ashar Sunyoto. (2008). Psikologi Industri dan Organisasi. Universitas Indonesia (UI-Press). Jakarta.

Murdiyanto, Agus. (2012). "Analisis Pengaruh Motivasi dan Lingkungan Kerja terhadap Kinerja Karyawan Motor Hepy Cabang Jawa Tengah”. Jurnal Tema. Vol. 9, No. 1, h. 12-28.

Nurcahyani, Ni Made dan I.G.A. Dewi Adnyani. (2016). "Pengaruh Kompensasi dan Motivasi terhadap Kinerja Karyawan dengan Kepuasan Kerja sebagai Variabel Intervening". E-Jurnal Manajemen Unud. Vol. 5, No.1, h. 500 - 532

Reksohadiprodjo, Sukanto dan Indriyo Gitosudarmo. (2009). Manajemen Produksi. BPFE. Yogyakarta.

Rivai, Veitzhal. (2012). Manajemen Sumber Daya Manusia Untuk Perusahaan: Dari Teori ke Praktik. Raja Grafindo Perkasa. Jakarta.

Sastrohadiwiryo, B.Siswanto. (2013). Manajemen Tenaga Kerja Indonesia. Bumi Aksara. Jakarta.

Sedarmayanti. (2007). Manajemen Sumber Daya Manusia. Pradnya Paramita. Jakarta.

Setyani, Tri Budi. (2014). "Analisis Pengaruh Kompensasi, Motivasi, Lingkungan Kerja dan Budaya Organisasi terhadap Kinerja Karyawan (Studi Kasus di Lingkungan 
Pegawai Kantor PDAM Boyolali)". Naskah Publikasi. Progam Studi Akuntansi Fakultas Ekonomi Dan Bisnis Universitas Muhammadiyah Surakarta.

Siagian, Sondang P. (2007). Manajemen Sumber Daya Manusia. Bumi Aksara. Jakarta. Sugiyono. (2010). Statistika untuk Penelitian. Alfabeta. Bandung.

Sumarsono, Sonny. (2009). Metode Riset Sumber Daya Manusia. Graha Ilmu. Yogyakarta.

Sutrisno, Edy. (2009). Manajemen Sumber Daya Manusia. Kencana. Jakarta.

Wibowo. (2007). Manajemen Kinerja. Raja Grafindo Persada. Jakarta.

Wijaya, Tanto dan Fransisca Andreani. (2015). "Pengaruh Motivasi Dan Kompensasi Terhadap Kinerja Karyawan Pada PT Sinar Jaya Abadi Bersama”. Jurnal Agora. Vol. 3, No. 2, h. 37-45.

Yani, Muhammad. (2012). Manajemen Sumber Daya Manusia. Mitra Wacana Media. Jakarta. 